\title{
FACTORS ASSOCIATED WITH PHYSICAL ACTIVITY IN PEOPLE WITH DIABETES
}

\author{
Elżbieta Sieńko-Awieraniów, ${ }^{1, A, ~ C, ~ D, ~ E ~ M a r t a ~ S t e ̨ p i e n ́-S ł o d k o w s k a, ~}{ }^{1, A, D}$

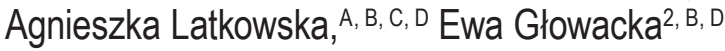 \\ ${ }^{1}$ Faculty of Physical Culture and Health Promotion, University of Szczecin, Poland \\ 2 Private Specialized Nursing Practice, Mierzyn, Poland

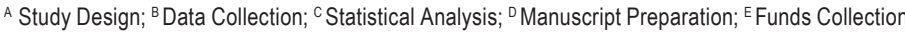 \\ Address for correspondence: \\ Elżbieta Sieńko-Awierianów, PhD \\ University of Szczecin, Faculty of Physical Education and Health Promotion \\ Al. Piastów 40B, building 6, 71-065 Szczecin, Poland \\ E-mail address: ela.sienko@wp.pl
}

\begin{abstract}
Ahstract. Background: Diabetes mellitus is a chronic disease related to the occurrence of numerous metabolic disorders. Their common feature is hyperglycaemia, caused by insufficient insulin secretion or its malfunction. The World Health Organization states that 346 million people worldwide have diabetes. The studies in adults with type 2 diabetes clearly demonstrate that the change of lifestyle behaviours effectively improves glycemic control. The modifications of lifestyle habits, such as regular physical activity and healthier dietary habits prove to be beneficial for patients. The aim of this study was to determine the factors affecting the level of physical activity in people with diabetes mellitus.

Methods: Research material consisted of the data gathered from a diagnostic survey, which was conducted in a form of a questionnaire. The study included 60 people with type 1 or type 2 diabetes.

Results: Unfortunately, the results show that not all of them were active enough, which is so crucial for stabilizing the disease.

Conclusions: The diagnosis of diabetes in the respondents resulted in more time being spent by them on physical activity, which resulted in the improvement of diabetes control and the normalization of body weight according to BMI, thus increasing the effectiveness of diabetes treatment and reducing complications. The frequency of the physical activity undertaken by the respondents prior to the disease was not related to gender, however, after the diagnosis, it was dependent on gender.
\end{abstract}

Key WOrdl: physical activity, diabetes mellitus, Body Mass Index, lifestyle

\section{Introduction}

Diabetes mellitus is a chronic disease related to the occurrence of numerous metabolic disorders. Their common feature is hyperglycaemia, caused by insufficient insulin secretion or its malfunction. Ninety percent of these disorders are related to type 2 diabetes - reduced insulin secretion by pancreatic islet cells or insulin resistance (Simmons et al. 2009). This type of diabetes has become epidemic in both developed and developing countries and is associated with rapidly occuring changes in lifestyle (Zhang et al. 2013). Type 1 diabetes is a chronic autoimmune 
disease characterized by progressive and selective destruction of pancreatic beta cells in genetically predisposed individuals during childhood or adolescence. It is triggered by the interaction between genetic and environmental factors (Bason et al. 2013).

The World Health Organization (WHO) states that 346 million people worldwide have diabetes (Roshan and Stanton 2013). In Europe, the index of morbidity related to diabetes ranges 3-6\% (Zatońska et al. 2011). In Poland, it reaches more than 5\%, which stands for 2 million people. It is also worth noting that $10 \%$ of the Polish population have hyperglycaemia, a pre-diabetic illness, which accounts for additional 4 million people. According to the predictions made by the International Diabetes Federation (IDF), the occurrence of diabetes worldwide will rise from $6.4 \%$ in 2010 to $7.7 \%$ in 2030, and a pre-diabetic state - from $7.8 \%$ in 2010 to $8.4 \%$ in 2030 (Sicree et al. 2009). The risks related to diabetes and a pre-diabetic state (such as impaired fasting glucose) include various diabetic complications: microvascular (retinopathy, nephropathy and neuropathy) and macrovascular (coronary heart disease and vascular diseases, including stroke) (Reyden et al. 2007; van den Brom et al. 2013). For example, in 20043.4 million people died of the complications associated with a high blood glucose level, and this number will double in the years 2005-2030 (Zatońska et al. 2011). 50\% of people with diabetes die from cardiovascular diseases. The complications of diabetes mellitus develop early, before any diagnosis can be made. About $50 \%$ of patients already have one chronic complication at the moment of diagnosis (Pranoto et al. 2014).

The disease is closely related to lifestyle behaviours, especially unhealthy and irregular eating habits and low physical activity. The occurrence of diabetes in people with abnormal body weight is 2-4 times higher (Zatońska et al. 2011). Until recently, type 2 diabetes was a disease of older people. However, in the past years it was also diagnosed in children, which is mostly due to the rising prevalence of obesity in this group. All risk factors for either pre-diabetes condition or the development of full-blown diabetes can be divided into non-modifiable risk factors, such as genetic factors, age and gestational diabetes, and modifiable risk factors: obesity, nutrition, physical activity or, for example, low birth weight or exposure to intrauterine diabetic environment (Pranoto et al. 2014). The studies in adults with type 2 diabetes clearly demonstrate that the change of lifestyle behaviours effectively improves glycemic control (Wittmeier et al. 2012). The modifications of lifestyle habits, such as regular physical activity and healthier dietary habits prove to be beneficial for patients (Daniele et al. 2013). Evidence suggests that regular physical activity can have positive effects on adults, for example improved disease self-management, weight loss, higher fitness, reduced medication usage and the improvement of HbA1c/fasting glucose (Plotnikoff et al. 2013). Therefore, the aim of this study was to determine the factors affecting the level of physical activity in people with diabetes mellitus.

\section{Materials \& Methods}

Research material consisted of the data gathered from a diagnostic survey, which was conducted in a form of a questionnaire. The study included 60 people with type 1 or type 2 diabetes. It involved 38 women and 22 men aged 18 to 70 years, who had filled in the survey in the period from January to February 2012. Prior to the study, the respondents acquainted themselves with the aim of the research and agreed to voluntary and anonymous participation.

All of the respondents completed the questionnaire containing 20 questions. It included the section with demographic and social data, such as age, gender, education, place of residence, as well as the part concerning 
physical activity levels in people with diabetes and the factors affecting it. Physical activity levels were assessed based on its frequency. Physical exercise undertaken 6-7 days a week was considered as high, 4-5 days moderate, and 2-3 days - low.

Data were also collected to determine the nutritional status of a respondent at the time of the study. It was assessed using Quetelet index: BMI (Body Mass Index) = [weight $(\mathrm{kg})] /[\text { body height }(\mathrm{m})]^{2}$. The data were classified through division into categories based on the nutritional status of the patients. The interpretation of the results was based on the criteria provided by the WHO in 2003 (Gertig 2006).

One of the considered parameters assessing the metabolic control of diabetes is glycated hemoglobin $\mathrm{HbA1c}$ (the normal value given by the Polish Diabetes Association in 2007: $\leq 6.5 \%$ ). Its value is used to evaluate the degree of metabolic control and the risk of chronic complications of diabetes (Sieradzki 2006). We also examined fasting blood glucose levels (the normal value in patients with diabetes provided by the Polish Diabetes Association in 2007: $\leq 110 \mathrm{mg} / \mathrm{dl})$.

The study also determined the blood pressure of the patients. They were checked according to the guidelines of the European (2007) and Polish (2011) Society of Hypertension (Grodzicki et al. 2012). The data received from the respondents were statistically analysed. $\chi^{2}$ test was conducted to analyse selected nonparametric values.

\section{Results}

Analysis of the education level of the respondents showed the prevalence of those with secondary education $-47 \%$ of the women and $46 \%$ of the men. The study involved far less people with vocational and primary education ( 8 and $5 \%$, respectively). In terms of occupation, the students ( $45 \%$ female) and the white-collar workers ( $41 \%$ of men and $34 \%$ of women) constituted the most numerous populations. The unemployed were the smallest group in the study (women $-3 \%$, men $-4 \%$ ).

The study showed that most of the respondents had type 1 diabetes mellitus (I): $92 \%$ of the women and $86 \%$ of the men. The percentage of the patients with type 2 diabetes mellitus (II) was quite low (8 and 14\%, respectively). The subjects injected insulin in order to regulate the blood glucose level, using pens ( $76 \%$ of the women and $68 \%$ of the men) or insulin pumps (respectively $16 \%$ and $18 \%$ ). $8 \%$ of the women and $14 \%$ of the men received medication in a form of an insulin pill.

The aim of this research was to evaluate the physical activity of the patients. We evaluated how many times per week the subjects took exercise and divided them into groups in relation to the frequency of these activities (Figure 1).

Most of the surveyed exercised 2-3 times a week. The results show that not all of them were active enough, which is so crucial for stabilizing the disease.

The evaluation of BMI values showed that a significant part of the respondents had normal weight $(86 \%$ of the women and $69 \%$ of the men). However, the study group also included women and men with underweight and obesity class (3\% and $4 \%$, respectively) and overweight ( $8 \%$ and $23 \%$ ). Sixty percent of the subjects who engaged in moderate physical activity had a normal nutritional status. Twelve percent of those with low physical activity and $8 \%$ of those who exercised intensely had a normal nutritional status as well. Overweight and obesity appeared far less frequently in the individuals who took part in various and intense physical activities ( $2 \%$ and $3 \%$, respectively). 


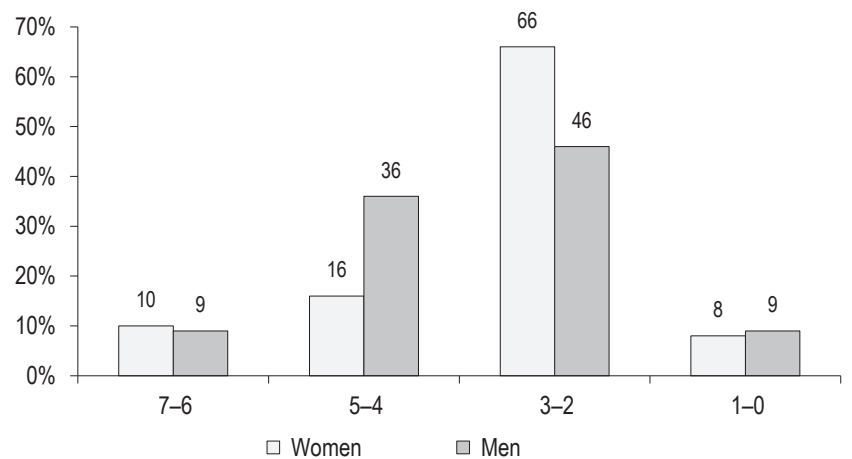

Figure 1. Frequency of physical activity per week in the study group

Prior to the diagnosis of diabetes, $15 \%$ of the respondents had exercised regularly, $57 \%$ had exercised occasionally and $28 \%$ had not exercised at all. After the onset of the disease the number of the respondents who exercised regularly more than tripled, whereas $43 \%$ of them stated that they still had been exercising occasionally. The data show that after the incidence of diabetes all of the subjects from the study group began to participate in physical activities, but in many cases they were still insufficient.

A form of physical activity favoured by both sexes was cycling (24\%) (Figure 2).

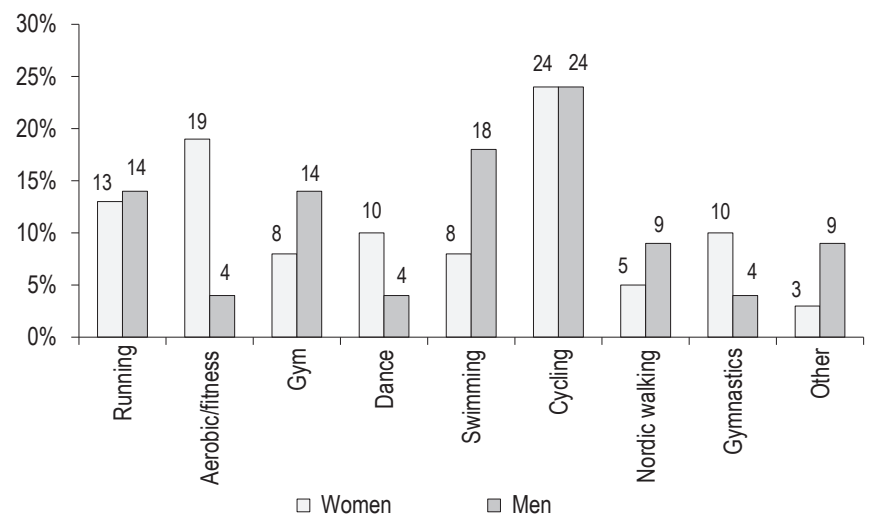

Figure 2. Preferred forms of physical activity in the study group

The male population preferred spending their free time swimming (18\%). A large percentage of the women $(19 \%)$ took aerobic/fitness exercises, while slightly lower percentage of them preferred dance and gymnastics (10\%). Gym exercises were also quite popular among the men (14\%). 
The site of drug injection prior to exercise is crucial for blood glucose levels afterwards. Most of the respondents answered that before exercise they injected insulin in the abdomen ( $58 \%$ of the women) and thigh ( $36 \%$ of the men) (Figure 3).

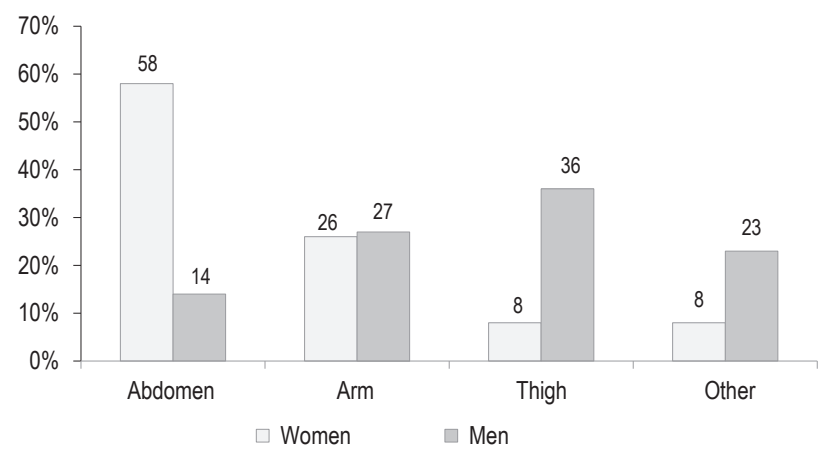

Figure 3. Sites of insulin injection prior to exercise

These are the regions which endure the most strain and determine the subsequent decrease in blood glucose levels. The respondents also pointed to other sites of insulin application such as buttocks and shoulder. Some of the subjects took insulin orally.

Most subjects ( $90 \%$ of women and $77 \%$ of men) declared that the administration of insulin into the body regions involved in exercise is important for glycemic control during physical activity. The patients also evaluated the effect of exercise on the blood glucose level. As many as $92 \%$ of the women and men reported that the blood sugar concentration decreased during physical activity. Less than $10 \%$ of the women and men claimed that they did not notice the effect of exercise on blood glucose levels. Eighty two percent of the women and $72 \%$ of the men observed that a low level of glucose persisted for over an hour after exercise, increasing the risk of unexpected hypoglycemia. Considerably fewer respondents felt it for less than an hour, and $5 \%$ of the women and $14 \%$ of the men had hypoglycemia for up to 30 minutes after physical activity.

The glycated hemoglobin levels of the subjects varied. $\mathrm{HbA1c}$ levels were within normal limits in $58 \%$ of the women and less than $23 \%$ of the men. The increased levels of this parameter were observed by more than half of the studied males (68\%), while $9 \%$ of the male respondents reported higher values of HbA1c. The blood sugar concentration observed before exercise reached analogical levels. A significant part of the respondents (57\%) had normal blood sugar levels (Figure 4). 


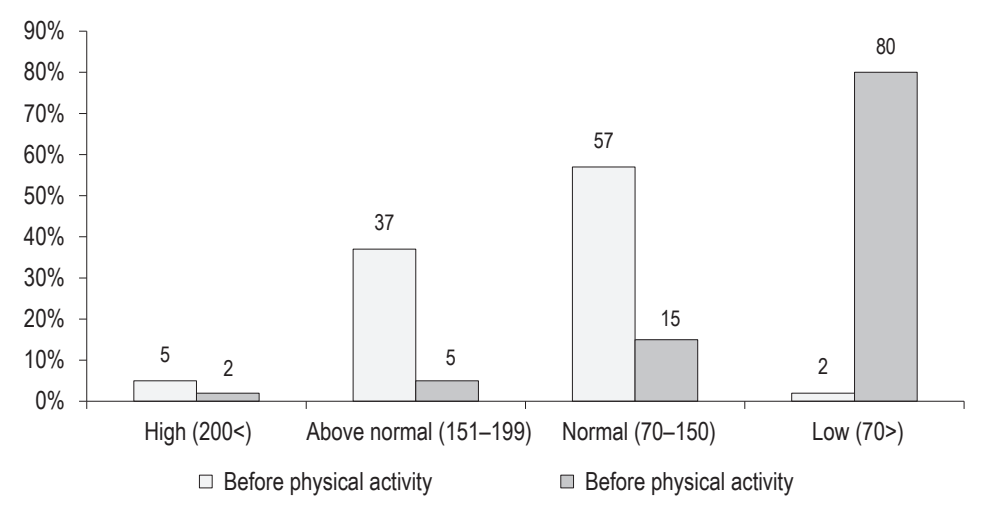

Figure 4. Blood glucose levels before and after exercise

$37 \%$ of the subjects reported increased glucose levels. $80 \%$ of the survey participants stated that after physical activity blood glucose stayed at low levels.

Majority of the study group had normal blood pressure ( $85 \%$ of the women and $77 \%$ of the men). $10 \%$ woman and $9 \%$ men had low blood pressure. The mental state associated with physical activity was assessed in all of the subjects. $95 \%$ of the women and $91 \%$ of the men reported feeling better after taking exercises. To determine the relationship between gender and physical activity before and after the onset of the disease, as well as the improvement of a mental state due to exercise in each gender, chi-square test $(\chi 2)$ was used. It was found that gender and the frequency of physical activity prior to the disease were independent, with the probability of type I error equal to 0.05 . After the onset of the disease, the frequency of physical activity and gender were dependent, with the probability of type I error equal to 0.05 . It was observed, however, that gender and the improvement of a mental state due to exercise were independent, with the probability of type I error equal to 0.05 .

\section{Discussion}

The diagnosis of diabetes should be followed by a change in lifestyle habits. In comprehensive diabetes care, besides treatment and medication, much emphasis is placed on a proper diet, education and physical activity (Sierakowska-Sitkiewicz and Karnafel 2008). Health habits play a significant role in the proper functioning of a patient with diabetes. Physical activity can prevent the premature development of diabetic complications, such as cardiovascular diseases, and reduce the unpleasant symptoms associated with the disease. Yet, for most people with diabetes it may be difficult to change habits (Centis et al. 2014). In addition, there is still a lack of knowledge on how to promote physical activity in people with type 1 diabetes mellitus (Quirk et al. 2014).

The survey which was conducted as a part of our study among people with diabetes brings optimistic results. One hundred percent of the respondents were aware of the significance of physical activity as an essential part of the therapeutic program for diabetics. They practiced regularly, whereas prior to the diagnosis nearly $30 \%$ of them did not participate in any physical activity at all.

A proper amount of physical exercise results in the improvement of the health status of a patient. According to the recommendations of the Polish Diabetes Association for the clinical management of patients with diabetes 
(2007), the best therapeutic effects of physical activity can be achieved when patients exercise regularly, preferably daily or at least 2-3 times a week. These recommendations were followed by the majority of respondents: $60 \%$ of them exercised 2-3 times per week, and more than 30\% engaged in physical activities even more frequently.

The study also showed that glycemic control is an important determinant of physical activity. Our research indicated that most of the respondents observed the improvement in diabetes control as a result of regular exercises.

The respondents agreed that the sites of insulin injection prior to exercise were related to the blood glucose levels observed afterwards (85\%) and that physical activity increased the effectiveness of diabetes treatment. 93\% of the respondents reported the improvement of their mental state thanks to physical exercises.

Numerous previous studies report the beneficial effects of physical activity on the prevention and treatment of the disease. Quirk et al. (2014), reviewing 23 publications issued in the years 1964-2012, demonstrate the potential health benefits for diabetics due to physical activity: a decrease in the levels of glycated haemoglobin (HbA1c), triglycerides and total cholesterol and the reduction of BMI.

More recent studies provide rich evidence that exercise facilitates controlling and maintaining normal blood glucose levels (Techmańska 2006). The study also reports numerous benefits of regular physical activity, including the reduction of body fat and blood sugar glucose, lowering blood pressure, decreasing the risk of diabetes complications, reducing the need for insulin, the maintenance of normal body weight, improvement of the blood circulation throughout the body, reducing the levels of "bad" cholesterol, etc. It is also reported that physical activity increases insulin sensitivity.

The study conducted by Zdrojowy and Sutkowska (2005) shows that in patients with diabetes who participate in sport activities, daily insulin requirement is reduced to up to $40 \%$. A large number of other authors also indicate the beneficial effects of physical exercises leading to the reduction of the stress and discomfort caused by the chronic disease and the overall improvement of mental state (Younk et al. 2009; Edmunds et al. 2007).

However, in the case of patients with well controlled diabetes, physical activity may lead to hypoglycaemia, if glucose depletion coincides with high levels of insulin and a lack of food intake. The risk of hypoglycemia occurring due to intense physical activity persists even for several hours afterwards - the fact that was also reported by our respondents. Therefore, physical exercise, which is considered an integral part of diabetes treatment, should be adapted specifically to the condition of a patient. Good information increases the benefits and safety of physical activity in patients with diabetes.

Efficient glycemic control may even allow diabetics to take part in professional sports and achieve great international successes. The most outstanding Polish athlete suffering from type 1 diabetes mellitus is Michał Jeliński, a rower competing in heavy weight quadruple sculls, the Olympic gold medallist from Beijing (2008), a fourtime world champion (2005, 2006, 2007, 2009) and 2010 European champion (Raczyńska et al. 2011). Another world-class rower with diabetes is Steve Redgrave, a five-time Olympic gold medallist (Los Angeles 1984, Seoul 1988, Barcelona 1992, Atlanta 1996, Sydney 2000). Another great athlete struggling with diabetes is an American swimmer, Gary Hall - a winner of five gold, three silver and two bronze medals at the Olympics. The participation of patients treated with insulin in competitive sports depends on developing individual insulin treatment schemes, adjusting insulin doses and adapting diet to the intensity and duration of physical activity (Techmańska et al. 2006).

These successful athletes prove that people with diabetes do not have to be excluded from professional and social life and they are capable of pursuing their personal goals. 


\section{Conclusions}

1. The diagnosis of diabetes in the respondents resulted in more time being spent by them on physical activity, which resulted in the improvement of diabetes control and the normalization of body weight according to BMI, thus increasing the effectiveness of diabetes treatment and reducing complications.

2. The frequency of the physical activity undertaken by the respondents prior to the disease was not related to gender, however, after the diagnosis, it was dependent of gender.

3. The improved mental state observed by the subjects due to participation in various forms of physical activity is independent of gender.

4. The injection of insulin in the body regions involved in exercise plays an important role in the reduction of blood glucose levels. In the women, the abdomen was the most frequent site of insulin injection prior to physical activity, while in the case of the men, it was the thigh.

5. If the sites of insulin injection are selected in accordance to the type of exercise, an extended period of the lowered blood glucose levels is observed by the diabetic subjects.

\section{References}

Bason C., Lorini R., Lunardi C., Dolcino M., Giannattasio A., d'Annunzio G., Rigo A., Pedemonte N., Corrocher R., Puccetti A. In type 1 diabetes a subset of anti-coxsackievirus b4 antibodies recognize autoantigens and induce apoptosis of pancreatic Beta cells. PLoS One. 2013; 8 (2): e57729.

Centis E., Trento M., Dei Cas A., Pontiroli A.E., De Feo P., Bruno A., Sasdelli A.S., Arturi F., Strollo F., Vigili De' Kreutzenberg S., Invitti C., Di Bonito P., Di Mauro M., Pugliese G., Molteni A., Marchesini G. Stage of change and motivation to healthy diet and habitual physical activity in type 2 diabetes. Acta Diabetol. 2014; 51 (4): 559-566.

Daniele T.M., Bruin V.M., Oliveira D.S., Pompeu C.M., Forti A.C. Associations among physical activity, comorbidities, depressive symptoms and health-related quality of life in type 2 diabetes. Arq Bras Endocrinol Metabol. $2013 ; 57$ (1): 44-50.

Edmunds S., Roche D., Stratton G., Wallymahmed K., Glenn S.M. Physical activity and psychological well-being in children with type 1 diabetes. Psychol. Health Med. 2007; 12: 353-363.

Gertig H., Przysławski J. Bromatologia. PZWL Warszawa 2006: 374.

Grodzicki T., Gryglewska B., Tomasik T., Windak A. Zasady postępowania w nadciśnieniu tętniczym. Gerontologia Polska. 2012; 20 (4): $119-147$.

Plotnikoff R.C., Costigan S.A., Karunamuni N.D., Lubans D.R. Community-based physical activity interventions for treatment of type 2 diabetes: a systematic review with meta-analysis. Front Endocrinol (Lausanne). 2013; 4: 3.

Pranoto A. Guidelines on the Management and Prevention of Prediabetes. The Indonesian Diabetes Association Diabetes and Nutrition Center, Comprehensive Diagnostic Center Building, Surabaya, Indonesia. Acta Medica Indonesiana - The Indonesian Journal of Internal Medicine. 2014; 46 (4).

Quirk H., Blake H., Tennyson R., Randell T.L., Glazebrook C. Physical activity interventions in children and young people with Type 1 diabetes mellitus: a systematic review with meta-analysis. Diabet Med. 2014; 31 (1): 1163-1173.

Raczyńska B., Zubik Ł., Jeliński M. Diabetes vs. physical exercise. Polish Journal of Sport and Tourism. 2011; 18: 3-16.

Reyden L., Standhl E., Bartnik M., Berghe GVd. Guidelines on diabetes, pre-diabetes, and cardiovascular disease. Betteridge J. Eur Heart J. 2007; 1-72.

Roshan B., Stanton R.C. A story of microalbuminuria and diabetic nephropathy. J Nephropathol. 2013; 2 (4): 234-240.

Sicree R., Shaw J., Zimmet P. The Global Burden, Diabetes and Impaired Glucose Tolerance. IDF Diabetes Atlas. 2009; (4th ed.): 1-15.

Sieradzki J., Grzeszczak W., Karnafel W., Wierusz-Wysocka B., Manikowski A., Szymoński T. Badanie PolDiab Część I. Analiza leczenia cukrzycy w Polsce. Diabetologia Praktyczna.2006; 7 (1).

Sierakowska-Sitkiewicz K., Karnafel W. Leczenie skojarzone cukrzycy typu 2. Nowa Klin. 2008; 15: $24-26$.

Simmons R.K., Unwin N., Griffin S.J. International Diabetes Federation: an update of the evidence concerning the prevention of type 2 diabetes. IDF Diabetes Atlas, (4th ed.) 2009. 
Techmańska I., Sieracki P., Myśliwiec M. Osiągnięcia sportowe a cukrzyca. In: Cukrzyca. Tom 1. Ed. J. Sieradzki. Via Medica, Gdańsk. 2006; 136-141.

Van den Brom C.E., Bulte C.S., Loer S.A., Bouwman R.A., Boer C. Diabetes, perioperative ischaemia and volatile anaesthetics: consequences of derangements in myocardial substrate metabolism. Cardiovasc Diabetol. 2013; 12 (1): 42.

Wittmeier K.D., Wicklow B.A., Sellers E.A., Griffith A.T., Dean H.J., McGavock J.M. Success with lifestyle monotherapy in youth with new-onset type 2 diabetes. Paediatr Child Health. 2012; 17 (3): 129-132.

Younk L., Tate D., Davis S. Physical activity in adolescents with type 1 diabetes: is more better for glycemic control? Ped. Diabetes. 2009; 10: 231-233.

Zatońska K., llow R., Regulska-llow B., Różańska D., Szuba A., Wołyniec M., Einhorn J., Vatten L., Asvold B.O., Mańczuk M., Zatoński W.A. Prevalence of diabetes mellitus and IFG in the prospective cohort 'PONS' study - baseline assessment. Annals of Agricultural and Environmental Medicine. 2011; 18 (2): 265-269.

Zdrojowy K., Sutkowska E., Adamiec R. Wysiłek fizyczny a kontrola metaboliczna cukrzycy. Med. Sportowa. 2005; $21: 370-372$.

Zhang F., Xu X., Zhang Y., Zhou B., He Z., Zhai Q. Gene expression profile analysis of type 2 diabetic mouse liver. PLoS One. 2013; 8 (3): e57766.

Cite this apticle aS: Sieńko-Awieraniów E., Stępień-Słodkowska M., Latkowska A., Głowacka E. Factors Associated with Physical Activity in People with Diabetes. Central European Journal of Sport Sciences and Medicine. 2015; 12 (4): 73-81. 
